\title{
Preliminary observations on myiasis in leprosy patients
}

\author{
SREEVATSA, G N MALAVIYA, S HUSAIN, \\ A GIRDHAR, H R BHAT* \& B K GIRDHAR \\ Central JALMA Institute for Leprosy, PB No. 31, Tajganj, Agra- \\ 282001, U P, India; and * National Institute of Virology, PB No. 11, \\ Pune-411 001, India
}

\section{Accepted for publication 21 May 1990}

\begin{abstract}
Summary Out of 3350 leprosy patients attending the surgical outpatient department for various ulcerative lesions, 18 patients had typical symptoms of myiasis. Maggots were collected in 5 cases from the nose, in 3 cases from ulcers of the hand and in 10 cases from ulcers of the foot. It was possible to rear the maggots into flies in 8 out of 18 cases. The flies were identified as Sarcophaga ruficornis and Chrysomyia bezziana.
\end{abstract}

\section{Introduction}

Myiasis is more prevalent in the tropics and subtropics where leprosy is also prevalent. It is known that about $65 \%$ of lepromatous leprosy (LL) patients have ulcerative lesions of the nose ${ }^{1}$ and about 10 to $20 \%$ of leprosy patients have ulcers in the foot and hand. ${ }^{2}$ The anaesthesia caused by leprosy leads to small injuries and recurrent injuries produce ulcers and suppuration. The anaesthetized suppurative ulcers become congenial for the flies for laying eggs or larvae. The tiny first instar maggots invade the wounds and living tissues and increase the size of the ulcers, thereby complicating the injury. Therefore, myiasis, when it occurs, should be considered as a serious problem.

The literature of myiasis in leprosy patients is scanty. A few to quote are the reports by Rao, ${ }^{3}$ Bose $^{4}$ and Tin Shwe ${ }^{5}$ who reported myiasis in leprosy patients and observed that suppurative leprosy wounds inside the nose provided an attractive site for flies to breed.

During the course of our observations at the Central JALMA Institute for Leprosy, about 40 to 50 leprosy patients came for treatment for myiasis every year. In most of the cases maggot infection was in the nose, plantar ulcers and in a few cases in the wounds of hands. Leprosy patients pose a specific problem of anaesthesia and ulceration with suppuration. This makes them more prone to myiasis than non-leprosy patients. Therefore this study has been undertaken to screen the leprosy patients attending the surgical OPD for various ulcer treatments for myiasis and to determine the incidence of myiasis and the causative dipteran fly. This report presents the preliminary observations. 


\section{Materials and methods}

Leprosy patients attending the surgical outpatient department of the Central JALMA Institute for Leprosy, Agra, during the year 1986-87 for various ulcerative lesions were screened for myiasis. Patients with specific symptoms of nasal myiasis such as sensation of gnawing or crawling in the nose, irritation, sneezing and maggots ejected while sneezing, intense facial cellulitis, headache, nasal obstruction, frank epistaxis and foul-smelling discharge mixed with blood and mucus, were examined for myiasis. Similarly patients with ulcers on hand and foot with considerable swelling, foul-smelling discharge of thick pus, crawling sensation in the wound and maggots falling out, were screened.

From the patients with myiasis in the nose, the maggots were collected by washing the nasal cavity with saline and also by asking the patient to blow his nose into a clean Petri dish. The nose of maggot infected patients was irrigated with a turpentine-water mixture $(1: 10)$ twice daily and plugged with paraffin soaked ribbon gauze after applying a few drops of liquid paraffin. This procedure was continued and maggots were picked up manually until the discharge from the nose subsided.

The maggots from infected wounds of the hand and foot were picked up manually by using a pair of blunt forceps and transferred to a clean Petri dish. The infected wounds were cleaned and dressed with gauze soaked in a turpentine-water mixture $(1: 10)$ twice a day. Maggots were removed manually until the wound became clean.

Maggots thus collected in Petri dishes were transferred to a beaker containing meat, and the beaker was covered with a cloth and kept at room temperature away from other flies. Fresh meat was substituted periodically when the larvae were found moving out from the old meat. A few of the 3rd stage larvae moving out for pupation from each sample were treated with $10 \%$ menthol solution for $10 \mathrm{~min}$, fixed in chloroform vapour and preserved in $70 \%$ alcohol for identification. The remaining $3 \mathrm{rd}$ stage larvae were transferred to a bowl containing sand and sawdust and allowed to pupate at room temperature. For identification later flies emerging from the pupae were held for $24 \mathrm{hr}$ for the cuticle to harden, killed by etherization and preserved by pinning in glass tubes impregnated with a thin layer of naphthalene.

\section{Results}

A total of 3350 leprosy patients attending the surgical OPD for various ulcerative lesions

Table 1. Incidence of myiasis on various body parts of the patients

\begin{tabular}{lcccc} 
Type of leprosy & Nose & Hand & Foot & Total \\
\hline LL & 5 & 1 & 3 & 9 \\
BT & 0 & 2 & 6 & 8 \\
Neuritic & 0 & 0 & 1 & 1 \\
\hline Total & 5 & 3 & 10 & 18 \\
\hline
\end{tabular}


Table 2. Incidence of myiasis cases during the year 1986-87

\begin{tabular}{lc}
\hline Month & Number of cases \\
\hline July and August 1986 & 2 \\
September and October & 9 \\
November and December & 6 \\
January to June 1987 & 1 \\
\hline Total & 18 \\
\hline
\end{tabular}

were screened for myiasis and 18 were found positive. Sites of infection in the various types of leprosy are shown in Table 1 .

Myiasis sex ratio was $1 \mathrm{~F}: 17 \mathrm{M}$. The ages of patients ranged from 18 to 75 years and their history of leprosy ranged from 3 to 26 years. Monthly incidence of myiasis coincided with the prevalence of flies (Table 2).

It was possible to rear the maggots into flies in 8 out of 18 cases. The flies were identified as Sarcophaga ruficornis Fab. (Sarcophagidae-Flesh Flies) in one case and Chrysomyia bezziana Villeneuve (Calliphoridae-Blow Flies) in the other seven cases.

\section{Discussion}

Myiasis is defined as the parasitism of living mammalian tissue by larvae of dipteran flies. The flies responsible for myiasis are grouped as specific (obligatory), semi-specific (facultative) or accidental parasites. ${ }^{6}$ This classification is based on the ovi-or larvipositing habits of the fly. Depending on the affected organ, the myiasis can also be classified as nasal, intestinal, aural, ocular, anal, vaginal, bladder or urinary tract. ${ }^{7}$

Rev. F W Hope ${ }^{8}$ was the first to coin the term myiasis. Goldstein ${ }^{9}$ was probably the first to report on myiasis in humans. The commonest genera causing myiasis in humans are Sarcophaga, Lucilia, Calliphora and Chrysomyia. Occasionally the common houseflies belonging to the genus Musca are also responsible for accidental myiasis in humans.

The maggots of certain species of dipteran flies are merely scavengers and sometimes found to be beneficial. These 'surgical maggots' are said to help in healing wounds. However it is very difficult to predict circumstances under which they act as scavengers or as serious parasites.

In leprosy maggot infestation is rare with an incidence of $0.5 \%$ in this report, but it can cause much distress, pain and increased tissue damage. In the present study the maggots that were identified were not the larvae of the common house-fly, and they were not even found beneficial in curing the ulcers. They were the flesh-eating ones responsible for specific and semi-specific myiasis. It was observed that myiasis in ulcers of the foot was more common than that of ulcers of the nose and hand. Occupation, age and sex were not seen as a major factor responsible for myiasis. The reason for getting more cases of myiasis during the post-monsoon season appears to be climatic and due to the increased prevalence of the flies. Poor personal hygiene as well as environmental conditions are the other compounding factors for myiasis. Flushing the ulcerative lesions with a turpentinewater mixture and manual removal of maggots were found to be the only way of treating 
these cases. Myiasis is an avoidable problem which can be prevented primarily by early treatment of leprosy and prevention of ulcers. Even if ulcers have occurred, myiasis can be prevented by proper ulcer care and preventing flies from settling on the ulcers by keeping them regularly covered with dressings.

\section{Acknowledgments}

We are thankful to Dr H Srinivasan, Director, for his comments and permission to publish this paper. We also thank Mr Rajendra F Lall for his technical assistance and $\mathrm{Mr}$ J D Kushwah for secretarial help.

\section{References}

1 Davey TF, Barton RPE. Leprous lesions of the nose, Chapter 12, Leprosy, Vol. 1, Dharmendra (ed), Bombay: Kothari Medical Publishing House, p. 168, 1978.

2 Srinivasan H, Dharmendra. Neuropathic ulceration, Chapter 18, Leprosy, Vol 1, Dharmendra (ed), Bombay: Kothari Medical Publishing House, p. 225, 1978.

${ }_{3}$ Rao GR. Myiasis in leprosy. Ind Med Gaz, 1929; 64: 380.

${ }^{4}$ Bose DN. Maggots in the nose of a lepromatous case of leprosy, Lepr India, 1960; 32: 181-2.

${ }^{5}$ Shwe Tin. Myiasis in necrotic tissue of a leprosy patient. Lepr Rev, 1987; 58: 306.

${ }^{6}$ Patton WS. Notes on the myiasis producing Diptera of man and animals. Bull Ent Res, 1921; 12: 239-61.

7 James MT. The flies that cause myiasis in man. Washington: US Dept Agri Mis Pub, 1947; 631: 1-175.

${ }^{8}$ Hope FW. On insects and their larvae occasionally found in the human body. Roy Ent Soc London Trans, 1840; 2: 256-71.

9 Goldstein MA. The texas screw-worm and its invasion of the nasal cavities. Laryngoscope, 1897; 3: 335-40. 